\title{
Constructing the boundary texture of Iranian urban rivers, case study (Shirin Rudi Sari River)
}

Construcción de la textura límite de los ríos urbanos iraníes, estudio de caso (río Shirin Rudi Sari)

Author:

Somayeh Noruzi,**

Shahrbanoo Samadai ${ }^{2}$

Mahdi Samadai ${ }^{3}$

\section{SCIENTIFIC RESEARCH}

How to cite this paper:

Noruzi. S., Samadai. S., Samadai. M. Constructing the boundary texture of Iranian urban rivers, case study (Shirin Rudi Sari River), Babol, Iran. Revista Innovaciencia. 2019; 7 (2): 1-7. DOI:

http://dx.doi.org/10.15649/2346075X.769

Reception date:

Received: 09 March 2019

Accepted: 30 April 2019

Published: 25 October 2019

Keywords:

Architecture, Water Reservoir, Urban Rivers, Shirin Rood

\section{ABSTRACT}

Architecture has long been seeking solutions for human well-being and comfort. In this regard, the existence of service spaces, welfare that both needs both indigenous people and non-native tourists, seems necessary. The development and management of urban rivers can be one of the choices that, in addition to preserving national resources and ecosystems, have an increasing role to play in improving the quality of the environment within the boundaries of the city's rivers. This topic focuses on water conservation and how it can be exploited, and how to use urban rivers and planning to achieve social, economic and environmental achievements along the city's riverside streams. The main problem is that in most cities, the boundaries of urban rivers are not regulated and the land abandoned around rivers. In the meantime, creating a calm environment away from environmental pollution and visual contamination is one of the major problems of modern cities, as well as providing suitable facilities for users to benefit from the beautiful scenery of the river can be a good solution for this important Be. This research is to study the case study of Shirin Roud River to the Shahid Rajaie Dam in Sari to study more accurately the environmental, social and economic challenges of urban rivers and provide appropriate solutions in this regard. In this study, both studies Library and field observations and setting up a questionnaire for access to theoretical foundations of design.

Corresponding author: Somayeh Noruzi

Technical faculty of I Ghodsiyeh Sari. Email: somi_architect@yahoo.com

Islamic azad university, Babol branch, Babol, Iran

Islamic azad university, Babol branch, Babol, Iran 


\section{INTRODUCTION}

Due to the lack of family and family entertainment and problems such as long distances, high costs of zero and a lack of some facilities, it seems that special attention can be paid to this category.

The busy and crowded spaces of cities and the need for people to a quiet and beautiful place that is not far from the city to rest and relaxation is a necessity of todayss society. Designing these spaces can be a great place for leisure and leisure for the people of that area as well as for the tourism industry and tourists. To attract tourists, the proper assessment of the location of the site to benefit from the facilities is important that urban rivers can be a good offer.

Urban rivers are the focus of the development of tourism and urban development. The role of water and management is one of the strategic axes of the urban area.

Nature, due to its environmental and inherent limitations, needs to be carefully studied and planned, but at the same time its optimal opportunities can be exploited. In the present century, due to the increasing urbanization and the intensification of changes in the type of human thinking about nature, the long-standing balance of man and nature has tended to dominate human dominance over nature. Also, decades ago, the need to change the attitude toward nature has been emphasized. Marginal natural cuisine and inland are natural potentials that the ecological continuity and survival of cities depend on these rich resources. Most of these natural sites are exposed to degradation due to lack of proper design and management, and gradually from sources the natural content in them is reduced. Ecological design, which these natural spaces can provide in addition to providing natural flood of cities, provide suitable food for the people of the city and surrounding cities. Among these natural spaces, mussels are urban rivers that have been severely damaged and raped in recent decades. In this study, we have tried to consider some of the solutions to this important issue.

\section{Water}

Water in the environment where rainfall processes flowing over the surface and penetrating into the earth. The construction of cities on the water cycle has been heavily affected, and it affects the soil and as a result of urban flora and fauna. The carved parts of streets, buildings, etc. prevent the penetration of water into the earth, and as a result, most of the water flows directly to the urban flood system. Types of urban water resources are similar to those found in non-urban and natural environments. However, the city conditions often have a major impact on the presence of living organisms at these stations.

The role of water in the formation of the first human habitats is a response to a biological need, but when it comes to urban areas, housing and construction of residential complexes, it takes social cultural times.

Understanding the rules of physical behavior of our water behavior is our feelings against the action and response of the water, and most importantly, the role and parable of its relation to human life. Water is one of the natural elements that has an unchanging nature, wherever it appears, its application should reflect the vitality and refreshing nature of which it originates. Access to water resources has long been considered as one of the most important factors in urban locating. The overall geographic survey of Iranian cities is well illustrated by the relationship between urban living and access to water resources. Therefore, research and implementation of waterrelated projects is important for considering the environmental impacts and impacts.

Environmental impacts represent material and immaterial actions that provide key information on environmental impacts, stakeholder relationships and organizational systems, and reflect definitions of the effectiveness and efficiency of environmental action.

\section{Urban rivers}

Urban streams and rivers are one of the most 
important natural complications that, due to their nature, have a significant impact on the formation, efficiency and recreation areas, tourism and urban areas. The margins of rivers can be a good platform for generating green spaces.

Arranging these lands, due to the considerable dispersion that they have on the road, has created more access to green spaces for citizens and also increases the per capita urban green space. Most cities have a space to be used as a natural space after urban planning and design to meet the urban nature's natural needs.

The topic that has been the subject of urban and regional designers in the last few decades is how to deal with such spaces in the field of urban physical development and points of interest in the realm of urban and regional projects.

Urban water and surrounding areas, in the event of efficient conservation and management, are social capital that can bring many visually and quality benefits to the citizens.

\section{Influence of rivers in the landscape and urban quality}

The urban landscape and quality are essentially dependent on visual perception, and this perception is related to beauty. The ideas of beauty are made up of cultural and social foundations. Therefore, it is important to recognize that the taste and taste of the public are wider than the standard of beauty for the particular environments. Characteristics of lovely environments from Jack Nascar's perspective are defined as follows:

- Good cleaning and maintenance

- Historic originality

- to have discipline

- Have normal color

- Open space and defined

Urban rivers, with the inherent nature of openness in the arena, cute and fluidity of nature, and having a constructive role as the main backbone of the city, have a remarkable originality and will create a beautiful environment. What in this area is our attention Demands to preserve the river basin and preserve its nature in the cleanliness of the river's water.

Getting a consecutive perspective along the course of the rivers leads to attracting human attention to the environment and creating more favorable effects. A long way in the direction of the water flow and the rivers edge is a good option for urban design, which is due to the irregularities of the times, the twists and turns naturally, there will be plenty of water and seating areas to sit down and see what's going on.

Together with each other, the city is livelier with each other, creating a more sophisticated vision of our attention to the surrounding environment. The link between the two existing views becomes apparent and the proportions between their components from the basics of visual continuity.

Given the above, the following indicators of spatial sequencing are suggested:

- Enclosure

- Establishing obstacles to long and direct paths

- The physical connection of the components with each other and with the whole

- Continuity of movement

- Order and proportions

- Define connections

- Tight and loose space

- Static and dynamic spaces

The study of how the river and the city together and the effects of rivers on urban life are one of the issues that are considered by experts and urban planners in urban planning.

The discussion that focuses more on the design of responsive environments for human needs is the quality of the environment, which includes three categories of overall quality:

- Functional quality

- Experimental and experimental quality

- Environmental quality 
Urban environments need to have a place of liveliness, good sense of belonging, role playing and human communication in order to be responsive to collective and individual needs.

This paper tries to investigate some of the environmental, social and economic problems that have been encountered in this source and urban potential by investigating the Shirin-rud River as one of the city's rivers in Iran, and proposing solutions to this problem.

\section{Case Study: Shirin Rood River}

Shirin Rood is located in Khorramabad village in Dodangeh district of Sari city, Mazandaran province. Its distance to Sari is $75 \mathrm{~km}$. This river is one of the most densely populated parts of the bay. The waters of this river are from the central Alborz Mountains and the danger of the Khrono Mountains, also known as the Alps of Iran. Shirin Rood is very cool and cold due to the interconnected trees and the hornless beeches and sunlight, and its temperature is often 10 to 15 degrees above zero. Which can be a good timeline for the summer season. Shirin Rood is not the same along the entire path. In the middle of the road to the Shahid Raja'i dam, which is also known as the dam of Solomon Tangeh, it comes out on the day after the gathering again of the output of the dam. This beautiful river passes through its spectacular cliffs, creating a small, large waterfall. Some of these staircase waterfalls and some others have relatively large ponds suitable for swimming and water.

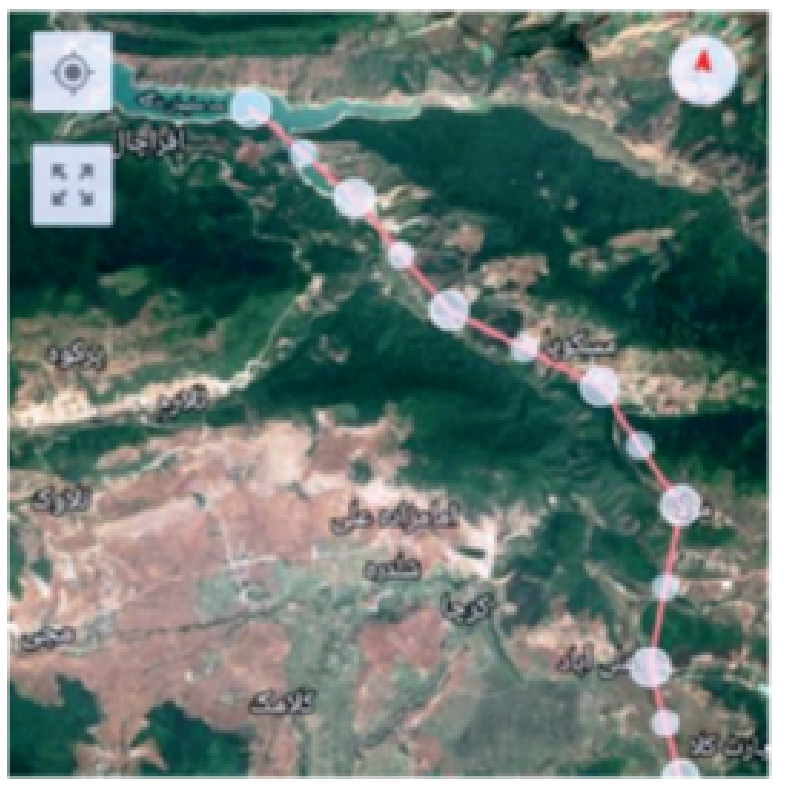

Figure 1: Sweet river flow position

The river's water is used to supply drinking water and agriculture. Shirin Roud River, due to its passage through the Shahid Rajaee dam, is always watery and can be a major axis for indigenous residents and non-indigenous tourists.

This natural environment, which is a coherent element, can increase the quality of the citys environment and affect the perception of the

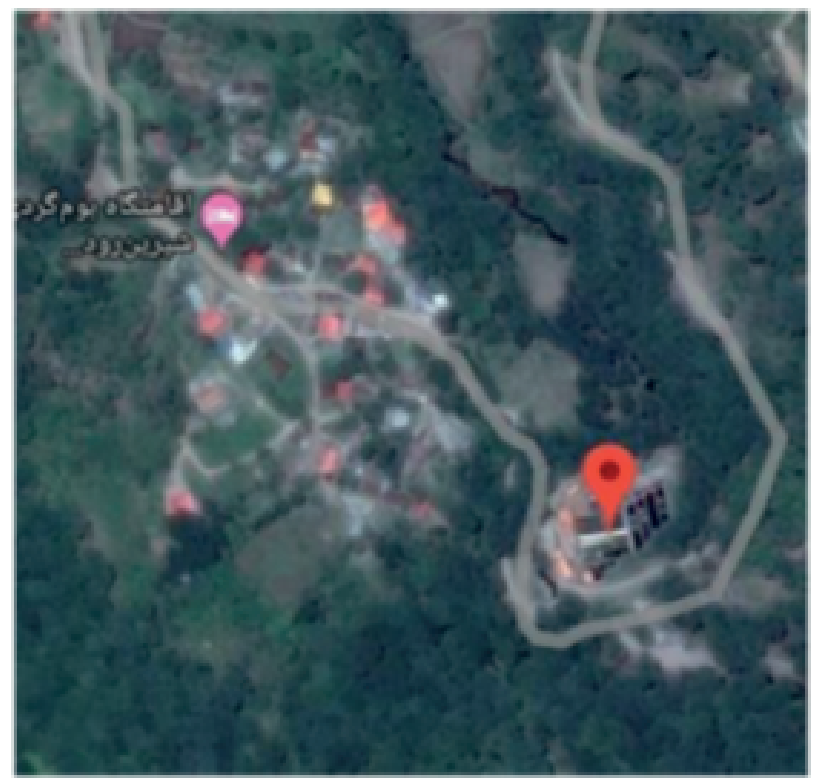

inhabitants of this city. It is a connecting platform for members of the cityss physical body and natural resources and meadows.

But the Shirin Roud River is in two parts of the maintenance of the margin of the river at the end of the Shahid Rajaee Dam and its stretching from the dam to the city and in the next section of the preservation of water resources, it is difficult, 
On the other hand, the beautification and creating of visual opportunities in the management of the margin of the river is less attention, the arrangement of the margin of the river Shirud can completely change the city and the boundaries of the city in such a way that people need a safe place to move and relax Ride the traffic to walk around places to relax and sit down for a variety and memorable place while still living in it.
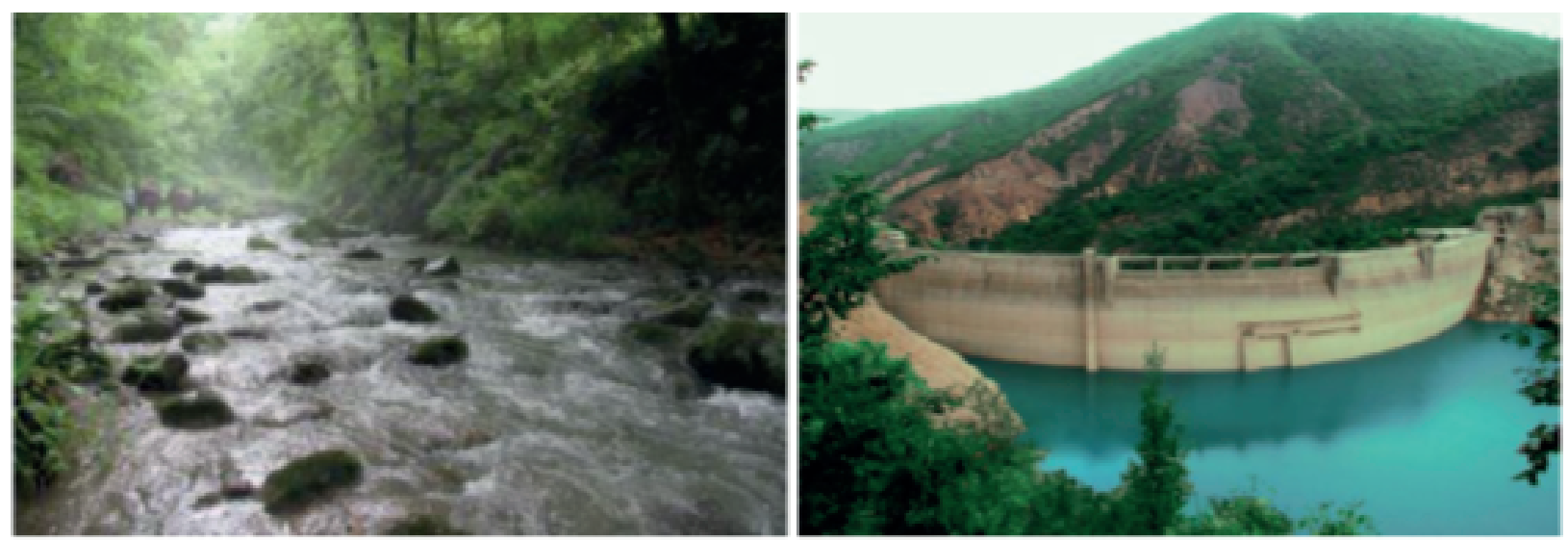

Figure 2: Location of Sweet River and Shahid Rajaee Dam

The results of this research were derived from descriptive-analytical research and library studies as well as observation and interviewing methods in the field of field studies of the Shirin River River. The descriptive method is based on library studies to analyze the relevant issues. Finally, by observing the shooting field and from the area in question, preparing different maps and a questionnaire from the people of this region, suggestions for improving the desired axis and promoting the natural landscape of the Shiroud River Presented. The statistical data obtained from the questionnaire were presented to the public in order to express the issues of the problems and deficiencies of the margin of the Shirin Roud River and the surrounding area. The table below shows.

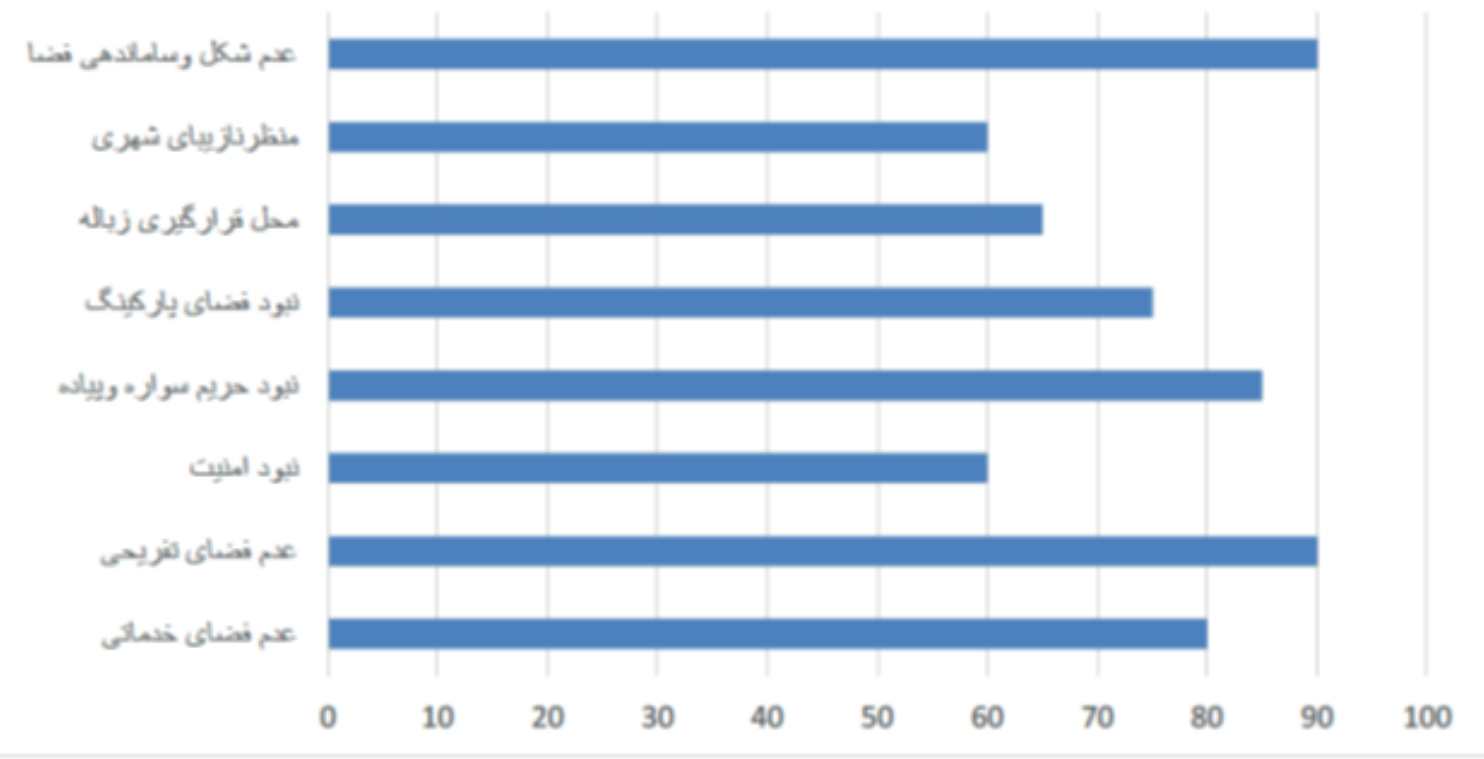

Figure 3: Graph of the results of the people's questionnaire in the area of shirin Roud area 
Table 1: Table of problems and solutions of Shirin Roud area: From the author

\begin{tabular}{ll}
\hline \multicolumn{1}{c}{ Strategies (Strengths) } & \multicolumn{1}{c}{ Problems (weaknesses) } \\
\hline Creating a space for temporary service and transit services along the river & $\begin{array}{l}\text { Lack of service space between a } \\
\text { temporary route for tourists }\end{array}$ \\
$\begin{array}{l}\text { Create a flea park space according to popular needs } \\
\text { The existence of undeveloped } \\
\text { land around the river }\end{array}$ & $\begin{array}{l}\text { Insecurity especially at night on } \\
\text { the river's edge }\end{array}$ \\
$\begin{array}{l}\text { Collecting waste garbage on the river border and transferring it to the create day-to-day service spaces that provide security and } \\
\text { outskirts of the river and creating buttons for controlling and disseminating } \\
\text { popular culture. }\end{array}$ & $\begin{array}{l}\text { Visual contamination based on } \\
\text { wasposal }\end{array}$ \\
$\begin{array}{l}\text { Creating recreational cultural space along the river's margin and optimizing } \\
\text { water use to create a relaxing atmosphere. }\end{array}$ & $\begin{array}{l}\text { Lack of proper design for using } \\
\text { river water }\end{array}$ \\
$\begin{array}{l}\text { Proper design of pauses and pre-spaces for entry and exit of pedestrians and } \\
\text { riders }\end{array}$ & $\begin{array}{l}\text { The lack of pre-spaces and slopes } \\
\text { for the ride path }\end{array}$ \\
$\begin{array}{l}\text { Designed to park the car at the right distance from each other } \\
\text { Design the edge of the river to a lively urban atmosphere and attraction of } \\
\text { tourism }\end{array}$ & $\begin{array}{l}\text { Lack of spaces for car parks } \\
\text { Vesigning and organizing the form and function of the routes and spaces } \\
\text { the river's margin }\end{array}$ \\
$\begin{array}{l}\text { used, collective, and ternary in the design of open spaces open and closed } \\
\text { spaces }\end{array}$ & $\begin{array}{l}\text { Lack of proper placement and } \\
\text { space organization }\end{array}$ \\
$\begin{array}{l}\text { Attraction and design of a suitable subterranean river to create vitality and } \\
\text { enhance social interactions between people and people with non-indigenous } \\
\text { tourists. }\end{array}$ & $\begin{array}{l}\text { Releasing the river as a natural } \\
\text { phenomenon }\end{array}$
\end{tabular}

\section{CONCLUSION}

The conservation and management of urban marginal rivers is very effective in increasing the quality of the urban environment. In this research, in order to obtain a better understanding of this concept, the Shirin River of Sari, Mazandaran province was selected. By reviewing the structure of this river, the following suggestions were proposed:

Identification of environmental factors and resources, Adopting measures to prevent urban wastewater entering the river boundaries, Managing the establishment of production, service and industrial units on the margin of Shirin Roud river, arranging the paths of riding and walking around the river, regular and sectional dredging of the river, Preparation and implementation of appropriate plans and programs in order to promote environmental culture and public education in this field, consolidation of the borders of the Shirin Roud River naturally, preservation and restoration and strengthening of the vegetation of the margin of Shirin Roud River, stabilization of high and dirty terraces In terms of safety and balancing for the cause Editing green spaces, planting plants to create green spaces around the river and turning them into a linear park, stepping the river wall to access water, creating amenities and services to enhance security, increasing the quality of urban environmental health, strengthening the impassable drive axis Motor 
vehicle, normal shape test of the subfloor of Shirin Rud River, promotion of environmental quality for human acceptance in it.

Organizing marginal areas of the Shirin Rud River of Mazandaran province, turning the feeling of undesirable into a pleasant feeling over its spaces requires planning, design, permanent management, application of spaces, and many other factors that it is hoped that this study could have been the basis of this important Has prepared.

\section{REFERENCES}

1. Abbaspour, Hossein, M. Environmental impacts of rivers on urban sustainability and architecture (analytical sample of the Souqi Chay River in Maragheh). Sustainable Architecture and Urban Development Conference, 2013

2. Wheeler-S Planning Sustainable and Livable Cities-In The City Ready (R.T.Legates and Fostout) Routedge- (1998

3. Lakhaee, Hasan Ali et al., Recreational design of the river-house area in the metropolitan environment, Tehran Center for Study and Planning (2009)

4. Henri-J \& Journeault-M Environmental Performance Indicators: An Empirical Study of Canadian Manufacturing Firms-Journal of Environmental Management -87-pp165-176 (2008). https://doi.org/10.1016/j.jenvman.2007.01.009

5. Aberkark, Tooling, Designing a Natural Inner City Walker with Environmental Perceptions (Case Study: Farrokhzad Valley) Environmental Master's Degree Dissertation, Faculty of Environment, Tehran University, Tehran, 1999

6. The Trustee, Massoud, A Study on the Quality of Beauty in the View of Shri Ermanashahr No. 5, 2010

7. Touzeli, Mahmoud, Principle of Communication in Urban Design, Quarterly in Fine Arts, No. 14, 1382

8. Golkar Kurosh, Conducting the Definition of Urban Design, Publishing the Samin Cultural and Artistic Institute, 1999 